\title{
N-Acetyltransferase 2 Genotype Correlates with Sulfasarazine Pharmacokinetics after Multiple Dosing in Healthy Japanese Subjects
}

\author{
Tomoko KITA, ${ }^{a}$ Toshiyuki SAKaEdA, ${ }^{a}$ Shin-ichi AdAchi, ${ }^{a}$ Toshiyuki SAKAI,${ }^{b}$ Nobuo Aoyama,,$c$ \\ Hisakatsu Hatanaka, ${ }^{d}$ Masato KasugA, ${ }^{b}$ and Katsuhiko OKUmURA ${ }^{*, a}$ \\ Department of Hospital Pharmacy, ${ }^{a}$ 2nd Department of Internal Medicine, ${ }^{b}$ Department of Endoscopy, ${ }^{c}$ School of \\ Medicine, Kobe University, Chuo-ku, Kobe 650-0017, Japan, and Hyogo Prefectural Institute of Public Health, ${ }^{d}$ Chuo-ku, \\ Kobe 650-0017, Japan. Received April 26, 2001; accepted July 12, 2001
}

Sulfapyridine (SP) is metabolized by polymorphic $N$-acetyltransferase 2 (NAT2) [EC 2.3.1.5]. In this study, the correlation between the NAT2 genotype and the pharmacokinetics of SP after multiple oral dosing of sulfasalazine (SASP) was examined to elucidate the effect of multiple dosing on the predictability of the phenotype by $N A T 2$ genotyping. Seven healthy subjects were classified into two groups; the homozygotes for the wild-type allele, $N A T 2 * 4 / * 4$ (Group I) and the compound heterozygotes for the mutant allele $(N A T 2 * 4 / * 6 A$ or $N A T 2 * 4 / * 7 B)$ (Group II). All received once-daily $1 \mathrm{~g}$ of SASP (Salazopyrin ${ }^{\circledR}$ ) orally for $8 \mathrm{~d}$. Plasma concentrations and urinary recoveries of SASP, SP and $N$-acetylsulfapyridine (AcSP) were monitored for $8 \mathrm{~d}$. At $24 \mathrm{~h}$ on Day 1 , the plasma concentration of SASP was lower and those of SP and AcSP were higher in Group II compared with Group I, but there was no significant difference. The plasma concentration ratio of AcSP to SP (AcSP/SP) tended to be lower in Group II. Urinary recoveries of SP and AcSP were increased in Group II, and their ratio was slightly reduced in Group II. Multiple dosing for $8 \mathrm{~d}$ resulted in an increase in the plasma concentrations of SASP, SP and AcSP. The difference between Group I and II was marked compared with single dosing, resulting in a significant difference in the plasma concentration of SP and the ratio of AcSP/SP. The simple input-output pharmacokinetic model applied for the analysis of plasma concentrations and urinary recoveries of SP and AcSP suggested the acetylation of SP into AcSP was 2.7-fold reduced in Group II $(p=0.064)$.

Key words $N$-acetyltransferase 2; genotype; sulfasalazine; multiple dosing; sulfapyridine

Sulfasalazine (SASP) has been commonly used in the treatment of inflammatory bowel diseases such as ulcerative colitis and Crohn's disease, and also in rheumatoid diseases. ${ }^{1,2)}$ After ingestion, SASP is split into a sulfapyridine (SP) and a 5-aminosalicylic acid (5-ASA) component by bacterial azo reductases in the colon and cecum, followed by acetylation of SP into $N$-acetylsulfapyridine (AcSP) by polymorphic $\mathrm{N}$-acetyltransferase 2 (NAT2) [EC 2.3.1.5] in the liver. $^{3-5)}$ Downstream from SP to AcSP-Gluc was restricted by NAT2 being in Group II compared with Group I (Fig. 1). NAT2 activity has been diagnosed by phenotyping, that is, administration of a test drug and subsequent determination of its plasma concentration and/or urinary recovery, and the subjects have been stratified into rapid, intermediate and slow acetylators. ${ }^{6-8)}$ Due to the toxicity of SP, adverse effects after SASP administration have been more frequently found in slow acetylators than rapid acetylators. ${ }^{9-11)}$ Dose individualization has been carried out according to the acetylator phenotype.

The polymerase chain reaction-restriction fragment length polymorphism (PCR-RFLP) method ${ }^{12)}$ was developed in the 1990's, which enabled the simple and rapid diagnosis of the protein function including NAT2 activity, compared with phenotyping. Patients need not to be exposed to any test drugs, and, therefore, it can be applied for dose individualization in routine patient care. ${ }^{13-17)}$ As for NAT2, it was demonstrated that the genotyping of three mutant alleles, $N A T 2 * 5 B$, $N A T 2^{*} 6 A$ and $N A T 2^{*} 7 B$, was adequate to determine the acetylator phenotype by a correlation study using healthy subjects and single dosing. ${ }^{13,14,18-20)}$ Rapid, intermediate and slow acetylator phenotypes were characterized by the homozygotes for the wild-type allele, the compound heterozygotes for the mutant allele, and the homozygotes for the mu- tant allele, respectively. This genotyping was expected to be promising in clinical applications, however, the effects of other factors arising from the clinical situation should be clarified including disease status, hepatic or renal functions, co-administered drugs, and multiple dosing, since these

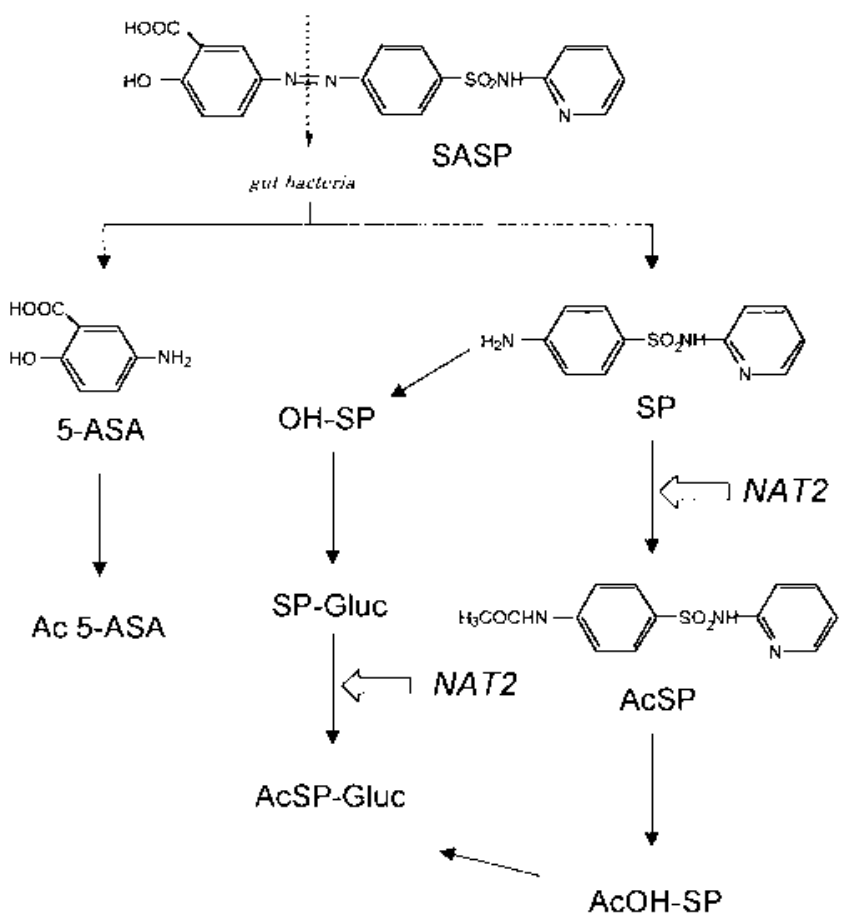

Fig. 1. Metabolic Pathways of SASP in Man

AcOH-SP $=N$-acetyl $5{ }^{\prime}-\mathrm{OH}$-sulfapyridine; $\mathrm{OH}-\mathrm{SP}=5^{\prime}-\mathrm{OH}$-sulfapyridine; $\mathrm{SP}-\mathrm{Gluc}=$ $5^{\prime}$-OH-sulfapyridine- $O$-glucuronide; AcSP-Gluc $=N$-acetyl $5^{\prime}$-OH-sulfapyridine- $O$-glucuronide; Ac 5-ASA= acetyl 5-aminosalicylic acid, respectively. 
sometimes induce the quantitative and qualitative alteration of enzymes, resulting in a change in the phenotype. Recently, we demonstrated that the first three had negligible effects on the correlation between genotype and acetylator phenotype. ${ }^{14)}$ In the present study, to elucidate the effect of multiple dosing on the predictability of the acetylator phenotype by NAT2 genotyping, the plasma concentrations and urinary recoveries of SP and AcSP were examined after multiple oral dosing of SASP in healthy Japanese subjects and those on the first day and the last day were compared. To analyze the pharmacokinetics of SP and AcSP after multiple oral dosing, a simple input-output function model was constructed and the mass-balanced equations were fitted to the plasma concentrations and urinary recoveries of SP and AcSP.

\section{MATERIALS AND METHODS}

Chemicals SP was purchased from Sigma Chemical Co. (St. Louis, MO, U.S.A.) as 4-amino- $N$-2-pyridinyl benzenesulfonamide. AcSP was synthesized following the method of Sharp et $a l .^{21)}$ The structural formula was analyzed by IR, GC-MS, and ${ }^{1} \mathrm{H}-\mathrm{NMR}$ (data not shown). All other chemicals were of reagent grade and obtained commercially.

NAT2 Genotyping Seven unrelated male Japanese subjects participated in this study. The NAT2 genotype was defined based on the wild-type allele $(N A T 2 * 4)$ or three mutant alleles $(N A T 2 * 5 B, N A T 2 * 6 A$ and $N A T 2 * 7 B)$, which was determined by the PCR-RFLP method as described previously. ${ }^{13,14)}$

The NAT2 genotypes were the homozygotes for the wildtype allele, $N A T 2 * 4 / * 4$ (Subjects No. 1-4), designated as Group I, and the compound heterozygotes for the mutant allele, $N A T 2 * 4 / * 6 A$ (Subjects No. 5 and 6) and $N A T 2 * 4 / * 7 B$ (Subject No. 7), designated as Group II. The population characteristics (mean \pm S.D.) of these two groups were comparable; Group I: age, 29.0 \pm 5.5 years; height, 168.5 \pm 4.4 $\mathrm{cm}$; weight, $59.5 \pm 7.8 \mathrm{~kg}$, Group II: age, $26.7 \pm 6.2$ years; height, $165.3 \pm 2.1 \mathrm{~cm}$; weight, $59.7 \pm 10.6 \mathrm{~kg}$. The aims of SP acetylator phenotyping study were fully explained to each subject, and written informed consent was obtained.

SP Acetylator Phenotyping Study Following Multiple Oral Dosing of SASP Each subject received once daily $1 \mathrm{~g}$ dose of SASP as a non-enteric coated Salazopirin ${ }^{\circledR}$ tablet (WelFide Co., Osaka, Japan) at 09:00 h after breakfast for $8 \mathrm{~d}$. They were prohibited to take any drugs from one week prior to SASP administration until the final blood and urine sampling. Blood samples were drawn at 3, 6, 9, 12 and $24 \mathrm{~h}$ after the first (Day 1) and final (Day 8) dosing of SASP, and before the dosing of SASP on Day 5. The blood samples were immediately centrifuged at $3000 \mathrm{rpm}(950 \times \boldsymbol{g})$ for 5 min to separate the plasma samples. Urine samples were also collected every $3 \mathrm{~h}$ up to $24 \mathrm{~h}$ after the first and final dosing of SASP. Each blank sample for the assay reference was obtained on the day before the first SASP administration. Both plasma and urine samples were stored at $-20^{\circ} \mathrm{C}$ until assayed. It was confirmed that there was no alteration of the sample by freezing.

Sample Processing The stocked plasma and urine samples were thawed at room temperature. The urine samples were centrifuged at $3000 \mathrm{rpm}(950 \times \boldsymbol{g})$ for $10 \mathrm{~min}$, and the supernatant was passed through a microporous membrane fil- ter $\left(0.45 \mu \mathrm{m}\right.$, MILLEX-HA ${ }^{\circledR}$, Nihon Millipore, Tokyo), then filtrated again through a $0.2 \mu \mathrm{m}$ filter $\left(\right.$ LCR4-LG ${ }^{\circledR}$, Nihon Millipore, Tokyo). If necessary, the urine sample was diluted 10-fold with $50 \mathrm{~mm} \mathrm{pH} 7.4$ phosphate buffer.

Determination of SASP, SP and AcSP Concentrations SASP, SP and AcSP concentrations in the plasma and urine samples were measured by HPLC as described previously. ${ }^{22,23)}$ Briefly, to determine the plasma concentration of SASP, each $100 \mu \mathrm{l}$ plasma sample containing the internal standard (sulfamethoxazole $5 \mu \mathrm{g} / \mathrm{ml}$ (final concentration)) was added with $300 \mu \mathrm{l}$ of methanol and mixed in a vortex mixer for $5 \mathrm{~s}$. The mixture was stored on ice for $10 \mathrm{~min}$, then centrifuged at $3000 \mathrm{rpm}(950 \times \boldsymbol{g})$ for $2 \mathrm{~min}$. Each $10 \mu \mathrm{l}$ of the supernatant was subjected to the HPLC analysis.

As for the plasma or urinary concentration of SP and AcSP, each $200 \mu \mathrm{l}$ of plasma or urinary sample containing the internal standard (sulfamethoxazole $5 \mu \mathrm{g} / \mathrm{ml}$ (final concentration)) was mixed with $200 \mu \mathrm{l}$ of $1 \mathrm{M}$ acetate buffer $(\mathrm{pH}$ 4.7 ) and $5 \mathrm{ml}$ of $\beta$-glucuronidase/arylsulfatase solution (5.2 $\mathrm{IU} / \mathrm{ml}$ ), which converted $5^{\prime}$-OH-sulfapyridine- $O$-glucuronide and $\mathrm{N}$-acetyl $5^{\prime}$-OH-sulfapyridine- $\mathrm{O}$-glucuronide to SP and AcSP, respectively, and then incubated at $37^{\circ} \mathrm{C}$ for $30 \mathrm{~min}$. Then, $800 \mu \mathrm{l}$ of methyl isobutyl ketone was added, and the mixture was shaken for $10 \mathrm{~min}$ and centrifuged for $2 \mathrm{~min}$. Eight hundred microliters of $0.1 \mathrm{M} \mathrm{NaOH}$ was added to 600 $\mu \mathrm{l}$ of the upper organic phase, and the mixture was shaken for $10 \mathrm{~min}$ and centrifuged for $2 \mathrm{~min}$. After discarding the upper organic phase, the water layer was washed with $600 \mu \mathrm{l}$ of dichloromethane and the mixture was shaken for $10 \mathrm{~min}$ and centrifuged for $2 \mathrm{~min}$. Each $20 \mu \mathrm{l}$ sample was subjected to the HPLC analysis.

HPLC (LC-6A, Shimadzu, Kyoto, Japan) was equipped with a system controller (SCL-6B, Shimadzu), a variable wavelength ultraviolet detector (SPD-6AV, Shimadzu) adjusted to $260 \mathrm{~nm}$, and a data processor (Chromatopac CR4A, Shimadzu). The stationary phase was a reversed phase Chemcobond 5-ODS-H column (4.6 mm i.d. $\times 250 \mathrm{~mm}$, particle size $5 \mu \mathrm{m}$, Chemco, Osaka, Japan). The mobile phase for the SASP assay was $12 \mathrm{~mm}$ phosphate buffer containing $0.06 \%$ tetrabutylammonium hydrogen sulphate:methanol $(40: 60, \mathrm{v} / \mathrm{v})$, and that for SP and AcSP assay was $20 \mathrm{~mm}$ phosphate buffer containing $0.1 \%$ tetrabutylammonium hydrogen sulphate: methanol $(77.5: 22.5, \mathrm{v} / \mathrm{v})$. The flow rate was $1.0 \mathrm{ml} / \mathrm{min}$ and the column temperature was maintained at $40{ }^{\circ} \mathrm{C}$. The retention time of SASP, SP, AcSP and the internal standard was 7.8, 9.5, 19.5 and $13.5 \mathrm{~min}$, respectively. The assay was carried out based on the peak area ratios of SASP, SP and AcSP to the internal standard. The calibration curves were linear over a concentration range of 0.125 to 20 $\mu \mathrm{g} / \mathrm{ml}\left(r^{2}>0.996\right)$ for SASP, 0.5 to $50.0 \mu \mathrm{g} / \mathrm{ml}\left(r^{2}>0.994\right)$ for SP and 0.2 to $50.0 \mu \mathrm{g} / \mathrm{ml}\left(r^{2}>0.994\right)$ for AcSP.

Pharmacokinetic Analysis To analyze the pharmacokinetic profiles of SP and AcSP after multiple oral dosing of SASP, the simple input-output pharmacokinetic model was constructed, where the input function was the oral administration of SASP, and the output function was the plasma concentration and urinary recovery of SP and AcSP (Fig. 2). The plasma concentration and urinary recovery of SP and AcSP were simultaneously fitted to the following mass-balanced equation utilizing a nonlinear least squares estimation based on the Runge-Kutta-Gill method. ${ }^{24)}$ 


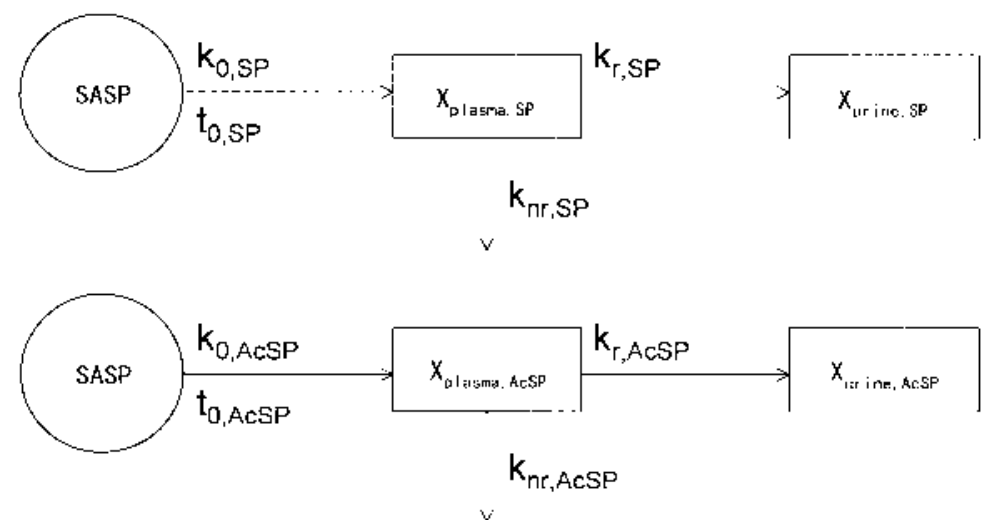

Fig. 2. Pharmacokinetic Model for SP and AcSP

$X_{\text {plasma }}=$ the amount in the central compartment; $X_{\text {urine }}=$ the amount excreted into urine; $k_{0}=$ the zero-order absorption rate constant; $k_{\mathrm{r}}=$ the first-order urinary elimination rate constant; $k_{\mathrm{nr}}=$ the first-order non-urinary elimination rate constant; $t_{0}=$ the lag time necessary for converting from SASP to SP or AcSP, respectively.

$$
\begin{aligned}
& d X_{\text {plasma, } \mathrm{SP}} / d t=F_{\mathrm{SP}}\left(k_{0, \mathrm{SP}}-C_{\text {plasma,SP}} V d_{\mathrm{SP}}\left(k_{\mathrm{r}, \mathrm{SP}}+k_{\mathrm{nr}, \mathrm{SP}}\right)\right) \\
& d X_{\text {urine, } \mathrm{SP}} / d t=F_{\mathrm{SP}} C_{\text {plasma,SP }} V d_{\mathrm{SP}} k_{\mathrm{r}, \mathrm{SP}} \\
& d X_{\text {plasma,AcSP}} / d t=F_{\mathrm{AcSP}}\left(k_{0, \mathrm{AcSP}}-C_{\text {plasma,AcSP }} V d_{\mathrm{AcSP}}\left(k_{\mathrm{r}, \mathrm{AcSP}}+k_{\mathrm{nr}, \mathrm{AcSP}}\right)\right) \\
& d X_{\text {urine,AcSP }} / d t=F_{\mathrm{AcSP}} C_{\text {plasma,AcSP}} V d_{\mathrm{AcSP}} k_{\mathrm{r}, \mathrm{AcSP}}
\end{aligned}
$$

where $X_{\text {plasma }}, X_{\text {urine }}, F, C_{\text {plasma }}$ and $V d$ are the amount in the central compartment, the amount excreted into urine, the oral bioavailability, the plasma concentration and the volume of the distribution, respectively. Parameters, $k_{0}, k_{\mathrm{r}}$ and $k_{\mathrm{nr}}$ are the zero-order absorption rate constant, the first-order urinary and non-urinary elimination rate constants, respectively. All equations were defined from the time, $t_{\mathrm{lag}, \mathrm{SP}}$ or $t_{\mathrm{lag}, \mathrm{AcSP}}$ to the time, $t_{\mathrm{lag}, \mathrm{SP}}+t_{0, \mathrm{SP}}$ or $t_{\mathrm{lag}, \mathrm{AcSP}}+t_{0, \mathrm{AcSP}}$, where $t_{\mathrm{lag}, \mathrm{SP}}$ or $t_{\mathrm{lag}, \mathrm{AcSP}}$ and $t_{0, \mathrm{SP}}$ or $t_{0, \mathrm{AcSP}}$ are the lag time necessary for converting from SASP to SP or AcSP and for starting the absorption, respectively. The difference between the values of $t_{\mathrm{lag}, \mathrm{AcSP}}$ and $t_{\mathrm{lag}, \mathrm{SP}}$ was statistically compared using the estimated mean values and their variation (mean \pm S.D.) for all cases, and $t_{\text {lag.AcSP }}$ was demonstrated to be larger than $t_{\mathrm{lag}, \mathrm{SP}}$, suggesting the justification of the calculation of their difference $\left(t_{\text {lag,AcSP }}-t_{\text {lag, SP }}\right)$ as the index of acetylation from SP to AcSP. In the case of the estimated mean value of $t_{\text {lag,AcSP }}$ was smaller than $t_{\text {lag,SP }}$, the value of zero was adopted as the data of $t_{\text {lag,AcSP }}-t_{\text {lag,SP. }}$.

Statistical analyses were performed using the unpaired $t$ test. Statistical significance was set at $p<0.05$.

\section{RESULTS}

Single Dosing Figure 3 shows the typical time-profiles of the plasma concentration of SP and AcSP following the oral administration of $1 \mathrm{~g}$ SASP once daily for $8 \mathrm{~d}$ in Subject No. 1 in Group I and Subject No. 5 in Group II. Compared with Subject No. 1, the plasma concentration of SP and AcSP increased slowly after oral administration in Subject No. 5. Table 1 lists the mean plasma concentrations of SASP, $\mathrm{SP}$ and AcSP at $24 \mathrm{~h}$ after SASP administration on Days 1 and 8 in Group I and Group II. At $24 \mathrm{~h}$ after single dosing of SASP (on Day 1), the plasma concentration of SASP was lower and those of SP and AcSP were higher in Group II than Group I, but there was no statistically significant difference. Plasma concentration ratios of AcSP to SP (AcSP/SP)

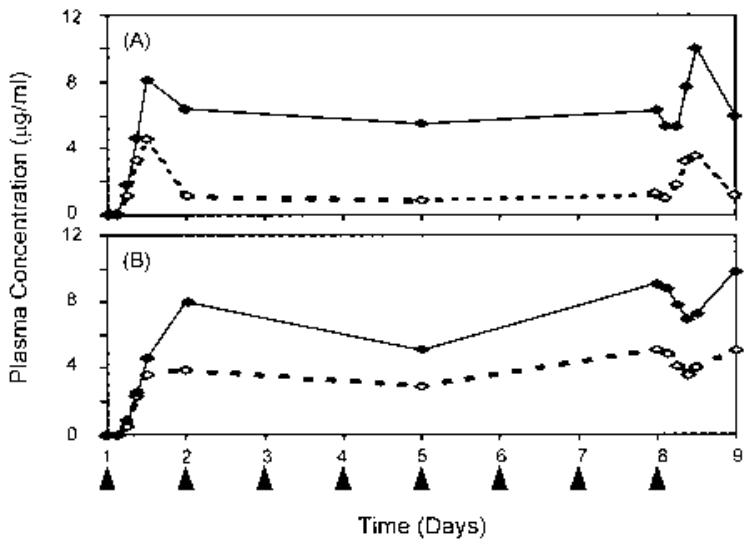

Fig. 3. Typical Time-Profiles of Plasma Concentration of SP $(\diamond)$ and AcSP $(\diamond)$ Following the Oral Administration of SASP Once Daily for $8 \mathrm{~d}$ in (A) Subject No.1 in Group I and (B) Subject No.5 in Group II

$\Delta$ shows the administration of $1 \mathrm{~g}$ oral dosing of SASP at 09:00 $\mathrm{h}$.

Table 1. Plasma Concentrations of SASP, SP and AcSP at $24 \mathrm{~h}$ after SASP Administration on Days 1 and 8 in Group I and Group II

\begin{tabular}{lccccc}
\hline \hline & \multicolumn{2}{c}{ Group I $(n=4)$} & & \multicolumn{2}{c}{ Group II $(n=3)$} \\
\cline { 2 - 3 } \cline { 5 - 6 } \cline { 5 - 6 } & Day 1 & Day 8 & & Day 1 & Day 8 \\
\hline SASP $(\mu \mathrm{g} / \mathrm{ml})$ & $3.0 \pm 2.1$ & $3.6 \pm 3.8$ & & $1.8 \pm 0.7$ & $2.3 \pm 1.1$ \\
$\mathrm{SP}(\mu \mathrm{g} / \mathrm{ml})$ & $2.0 \pm 1.1$ & $2.0 \pm 1.2$ & & $3.6 \pm 0.5$ & $5.2 \pm 0.6^{*, * *}$ \\
$\mathrm{AcSP}(\mu \mathrm{g} / \mathrm{ml})$ & $6.1 \pm 2.1$ & $7.5 \pm 2.2$ & & $8.3 \pm 3.9$ & $10.3 \pm 4.5$ \\
AcSP $/ \mathrm{SP}$ & $3.4 \pm 1.6$ & $4.2 \pm 1.1$ & & $2.3 \pm 0.9$ & $1.9 \pm 0.6^{*}$ \\
\hline
\end{tabular}

Each value represents the mean \pm S.D. $\# p<0.05$ compared with Day $1 . \quad * p<0.05$ compared with Day 8 in Group I. $* * p<0.01$ compared with Day 8 in Group I.

tended to be lower in Group II than Group I. Open columns in Fig. 4 show the urinary recoveries of SP and AcSP (\% of dose), and the urinary recovery ratio of AcSP/SP after single oral dosing of SASP. Although there was no significant difference between Group I and Group II, the urinary recoveries of SP and AcSP or the urinary recovery ratio of AcSP/SP in Group I was lower or higher than Group II. All findings on urinary recoveries corresponded to those on the plasma concentrations, suggesting no alteration of renal function.

Multiple Dosing Multiple oral dosing of SASP for $8 \mathrm{~d}$ resulted in increases in the plasma concentrations of SASP, SP and AcSP (Table 1, Fig. 3) and urinary recoveries of SP 

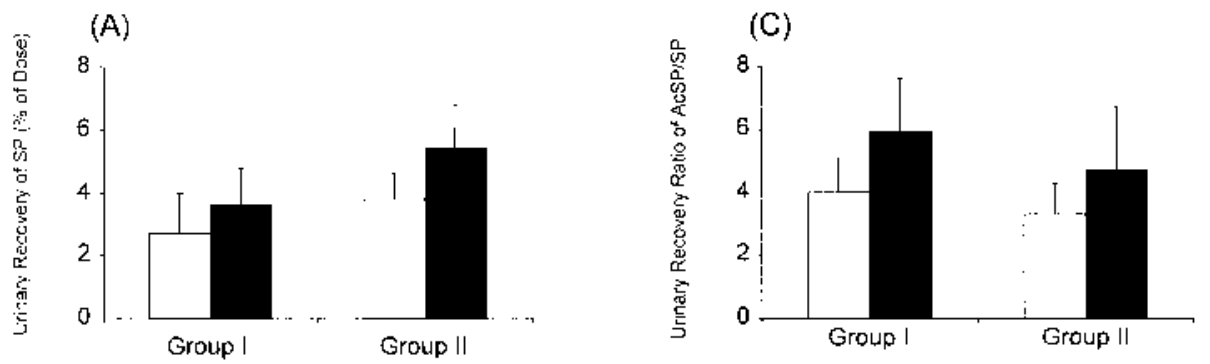

(B)

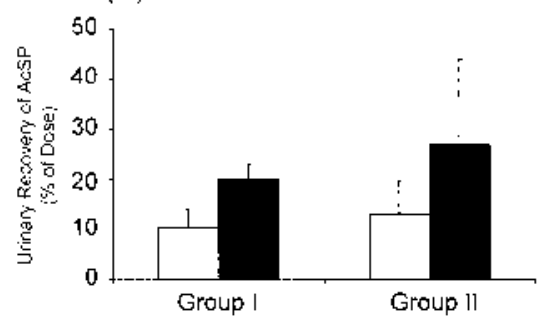

Fig. 4. Urinary Recoveries of (A) SP and (B) AcSP, and (C) Urinary Recovery Ratio of AcSP/SP in Group I and Group II on Day 1 (Open Columns) and Day 8 (Closed Columns)

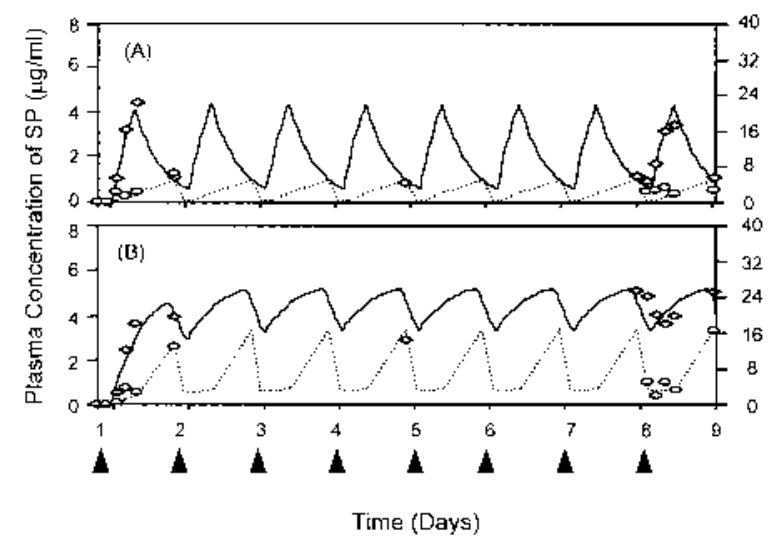

Fig. 5. Fitting Curves for the Plasma Concentration $(\diamond)$ and Urinary Recovery $(O)$ of SP in (A) Subject No. 1 in Group I and (B) Subject No. 5 in Group II

$\Delta$ shows the administration of $1 \mathrm{~g}$ oral dosing of SASP at $09: 00 \mathrm{~h}$.

and AcSP (Fig. 4) both for Groups I and II, suggesting the accumulation of SASP, SP and AcSP.

Similar to single dosing, the plasma concentration of SASP at $24 \mathrm{~h}$ following the last dosing on Day 8 was lower, and those of SP and AcSP were higher in Group II (Table 1, Fig. 3). The plasma concentration ratios of AcSP/SP was lower in Group II than Group I, with statistical significance (Table 1). The urinary recoveries of SP and AcSP were increased, but the urinary recovery ratio of AcSP/SP was reduced more in Group II than Group I (Fig. 4). The urinary recovery on Day 8 also reflected the findings derived from the plasma samples.

Pharmacokinetic Analysis Figure 5 shows the fitting curves for the plasma concentration and the urinary recovery of SP in Subject No. 1 and Subject No. 5. Figure 6 shows the AcSP findings. As shown in Figs. 5 and 6, the constructed model used here well-described the pharmacokinetics of SP and AcSP after multiple oral dosing of SASP. Compared with Subject No. 1, the fluctuation in the plasma concentrations of SP and AcSP was diminished in Subject No. 5.

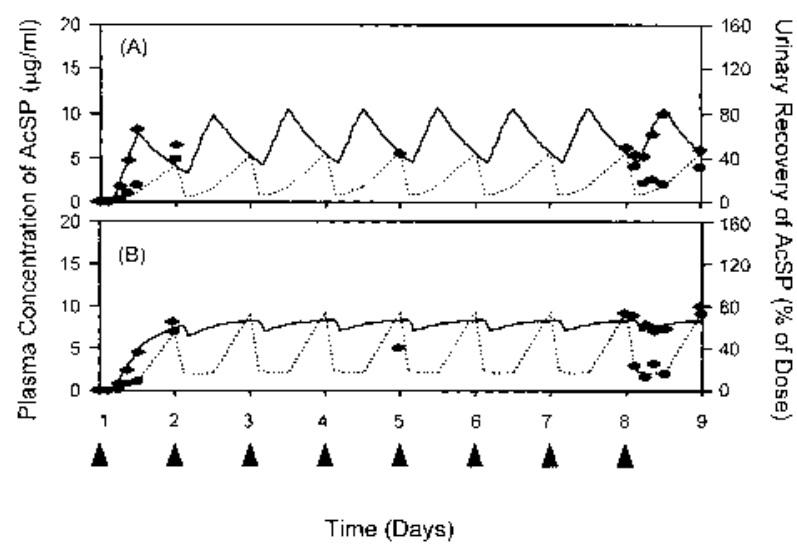

Fig. 6. Fitting Curves for Plasma Concentration $(\diamond)$ and Urinary Recovery (-) of AcSP in (A) Subject No. 1 in Group I and (B) Subject No. 5 in Group II

A shows the administration of $1 \mathrm{~g}$ oral dosing of SASP at $09: 00 \mathrm{~h}$.

Table 2. Pharmacokinetic Parameters of SP and AcSP in Group I and Group II

\begin{tabular}{lcccccc}
\hline \hline & \multicolumn{2}{c}{ Group I $(n=4)$} & & \multicolumn{2}{c}{ Group II $(n=3)$} \\
\cline { 2 - 3 } \cline { 5 - 6 } & SP & AcSP & & SP & AcSP \\
\hline$k_{\mathrm{r} n}+k_{\text {nr }}\left(\mathrm{h}^{-1}\right)$ & $0.12 \pm 0.05$ & $0.11 \pm 0.09$ & & $0.13 \pm 0.05$ & $0.13 \pm 0.03$ \\
$t_{\text {lag }}(\mathrm{h})$ & $5.4 \pm 3.1$ & $5.5 \pm 3.4$ & & $4.2 \pm 0.5$ & $5.1 \pm 0.6$ \\
$t_{\text {lag,AcSP }}-t_{\text {lag,SP }}(\mathrm{h})$ & $0.31 \pm 0.36$ & & & $0.83 \pm 0.15^{a)}$
\end{tabular}

Each value represents the mean \pm S.D. a) $p=0.064$ compared with Group I.

Estimated parameters concerning the pharmacokinetics of SP and AcSP in Group I and Group II are listed in Table 2. The elimination rates, $k_{\mathrm{r}}+k_{\mathrm{nr}}$ of SP and AcSP from the systemic circulation were comparable between Groups I and II. There was no difference in SASP absorption, $t_{\text {lag,SP. The }}$ metabolic conversion rate from SP to AcSP was assessed as the difference of $t_{\mathrm{lag}}$, and was 2.7-fold reduced in Group II compared with Group I ( $p=0.064)$. 


\section{DISCUSSION}

In the drug therapy, interindividual variability occurs in the pharmacokinetics and pharmacodynamics of drugs. These variations could be explained, in part, by the polymorphisms in the drug metabolizing enzymes and the susceptibility to drugs. ${ }^{25,26)}$ Recently, several mutant alleles which determine their activities have been found in each gene, and the relationships between the genotype and phenotype were elucidated in healthy subjects with single dosing..$^{13,18-20,27)}$ It is necessary for the application of clinical genotyping to clarify the effect of other factors arising from the clinical situation; disease status, hepatic or renal functions, co-administrated drugs, and multiple dosing. We previously reported that the acetylator phenotype was also predictable from the NAT2 genotyping even for tuberculous patients, and that co-administrated drugs and hepatic dysfunction did not appear to influence the predictability. ${ }^{14)}$ In general, it is known that multiple doses of drugs induce metabolic enzymes and transporters, enlarge the hepatic tissues, and increase the hepatic, blood and bile flow. ${ }^{28)}$ Herein, the effect of multiple dosing on the predictability of the acetylator phenotype by NAT2 genotyping was examined.

As for single dosing of SASP, plasma disappearance of SP and its acetylation into AcSP were reduced in Group II (the compound heterozygotes for the mutant allele) than Group I (the homozygotes for the wild-type allele), but there was no significant difference. However, the difference was manifested following multiple dosing (Table 1), resulting in significant differences. Multiple dosing induced the reduction of acetylation of SP more easily for Group II compared with Group I. NAT2 encoded by the mutant allele might be susceptible to reduction of enzymatic activity following multiple dosing. These findings suggested conducting a correlation study between the genotype and phenotype after multiple dosing. It was suggested that the multiple dosing has a negligible effect on the predictability of the phenotype by genotyping.

In this study, the simple input-output function model was constructed to analyze the pharmacokinetics of SP and AcSP after multiple oral dosing. Model fitting analysis suggested a decrease in the acetylation of SP into AcSP when the mutant allele was contaminated.

The metabolic conversion rate from SP to AcSP was assessed as the difference of, and was 2.7-fold reduced in Group II compared with Group I. Although there was no significant difference of $t_{\mathrm{lag}, \mathrm{AcSP}}-t_{\mathrm{lag}, \mathrm{SP}}$ between Group I and Group II $(p=0.064)$, the consistency with the findings of the plasma concentration supported the constructed pharmacokinetic model (Tables 1,2). This simple pharmacokinetic model would be a useful tool for the analysis of pharmacokinetics after multiple dosing.

A series of studies has been conducted on the correlation between the acetylator phenotype and the NAT2 genotype using procainamide, ${ }^{13)}$ isoniazid ${ }^{14)}$ and SASP, and the following conclusions were obtained; 1) rapid, intermediate and slow acetylator phenotypes were characterized by the wildtype allele, $N A T 2 * 4 / * 4$ and three mutant alleles, $N A T 2 * 5 B$, $N A T 2 * 6 A$ and $N A T 2 * 7 B, 2)$ disease status including renal and hepatic dysfunction or co-administration of other drugs had negligible effects on the predictability of the acetylator phenotype by NAT2 genotyping, and 3) multiple dosing also had negligible effects. Consequently, it was suggested that the genotyping of drug metabolizing enzymes could be a useful alternative to therapeutic drug monitoring in clinical situations.

\section{REFERENCES}

1) Peppercorn M. A., Ann. Intern. Med., 3, 377-386 (1984).

2) Rains C. P., Noble S., Faulds D., Drugs, 50, 137-156 (1995).

3) Klotz U., Clin. Pharmacokinet., 10, 285-302 (1985).

4) Das K. M., Dubin R., Clin. Pharmacokinet., 1, 406-425 (1976).

5) Das K. M., Eastwood M. A., McManuts J. P. A., Sircus W., Gut, 14, 631-641 (1973).

6) Evans D. A. P., Pharmacol. Ther., 42, 157-234 (1989).

7) Evans D. A. P., "Pharmacogenetics of Drug Metabolism," ed. by Kalow W., Pergamon Press, New York, 1992, pp. 95-178.

8) Sunahara S., Urano M., Ogawa M., Science, 134, 1530-1531 (1961).

9) Azad A. K., Howes D. T., Piris J., Truelove S. C., Gut, 21, 232-240 (1980).

10) Das K. M., Eastwood M. A., McManus J. P. A., Sircus W., N. Engl. J. Med., 289, 491-495 (1973).

11) Schroder H., Evans D. A. P., Gut, 13, 278-284 (1972).

12) Deng G. R., Nucleic Acids Res., 16, 6231 (1988).

13) Okumura K., Kita T., Chikazawa S., Komada F., Iwakawa S., Tanigawara Y., Clin. Pharmacol. Ther., 61, 509-517 (1997).

14) Kita T., Tanigawara Y., Chikazawa S., Hatanaka H., Sakaeda T., Komada F., Iwakawa S., Okumura K., Biol. Pharm. Bull., 24, 544-549 (2001).

15) Tanigawara Y., Aoyama N., Kita T., Shirakawa K., Komada F., Kasuga M., Okumura K., Clin. Pharmacol. Ther., 66, 528-534 (1999).

16) Kita T., Tanigawara Y., Aoyama N., Hohda T., Saijoh Y., Komada F., Sakaeda T., Sakai T., Kasuga M., Okumura K., Pharm. Res., 18, 615621 (2001).

17) Tanigawara Y., Kita T., Makimoto H., Sakaeda T., Komada F., Okumura K., Ther. Drug Monitor., 23, 341-346 (2001).

18) Deguchi T., Mashimo M., Suzuki T., J. Biol. Chem., 265, $12757-$ 12760 (1990).

19) Abe M., Deguchi T., Suzuki T., Biochem. Biophys. Res. Commun., 191, 811-816 (1993).

20) Mashimo M., Suzuki T., Abe M., Deguchi T., Hum. Genet., 90, 139143 (1992).

21) Sharp M. E., Wallace S. M., Hindmarsh K. W., Brown M. A., Can. J. Pharmaceutic. Sci., 15, 35-38 (1980).

22) Show P. N., Sivner A. L., Aarons L., Houston J. B., J. Chromatogr., 274, 393-397 (1983).

23) Chungi V. S., Rekhi G. S., Shargel L., J. Pharm. Sci., 78, 235-238 (1989).

24) Yamaoka K., Nakagawa T., J. Pharmacobio-Dyn., 6, 595-606 (1983).

25) Nebert D. W., Clin. Genet., 56, 247-258 (1999).

26) Arledge T., Freeman A., Arbuckle J., Mosteller M., Manasco P., Drug Metab. Rev., 32, 387-394 (2000).

27) Meyer U. A., Zanger U. M., Annu. Rev. Phramacol. Toxicol., 37, 269296, (1997).

28) Klaassen C. D., Watkins J. B., III, J. Pharmacol. Rev., 36, 1-67 (1984). 